\title{
Prof. Lunxu Liu: the demand for surgery will only go up instead of down
}

Submitted Nov 25, 2018. Accepted for publication Dec 06, 2018.

doi: $10.21037 /$ jtd.2018.12.28

View this article at: http://dx.doi.org/10.21037/jtd.2018.12.28

\section{Editor's note}

The 3rd Ruijin International Thoracic Symposium was held in Shanghai from November 15-16, 2018. With a focus on the latest advances of minimally invasive treatment of thoracic cancers, the symposium brought together numerous top national and international experts to discuss and exchange ideas on a series of hot topics in the field of thoracic surgery.

During the meeting, we were honoured to conduct an exclusive interview with Prof. Lunxu Liu (Figure 1), Director of Department of Thoracic Surgery, West China Hospital of Sichuan University, who will share his insights into the future development of thoracic surgery and prevention of perioperative complications. Please watch the video below for the entire content.

\section{Expert introduction}

Prof. Lunxu Liu, MD, is the Director of Department of Thoracic Surgery, West China Hospital of Sichuan University, Chengdu, China. He received his MD degree and $\mathrm{PhD}$ degree at West China University of Medical Sciences. He is considered a pioneer in performing complete video-assisted thoracic surgery (VATS) for lung cancer in Mainland China. He raised the concept of "single-direction VATS lobectomy", which made VATS lobectomy more concise and easier to learn and was widely used by most Chinese thoracic surgeons. He developed the novel method of "suction-compressing angiorrhaphy technique (SCAT)" for troubleshooting vascular injury during anatomic thoracoscopic pulmonary resection without conversion to thoracotomy. He also completed the first series of thoracoscopic bronchovascular doublesleeve lobectomy in the world. As project leader, Prof. Liu received the first prize of Sichuan Province Science and Technology Progress Award and Chinese Medical Science and Technology Award, respectively, for his great efforts

and achievements in minimally invasive thoracic surgery.

Prof. Liu is currently a Fellow of The Royal College of Surgeons (RCS). He serves as Vice-chair of Chinese Association of Thoracic Surgeon (CATS). He is also Chair of the Experts Committee on Minimally Invasive Surgery of CATS. Meanwhile, he is Deputy Leader of both Thoracoscopic Surgery Study Group and Lung Cancer Study Group of the Chinese Society for Thoracic and Cardiovascular Surgery. Besides, he has also taken up several leadership roles in multiple academic societies.

Prof. Liu's major clinical and research interests include minimally invasive thoracic surgery and lung cancer. $\mathrm{He}$ has been in charge of more than 10 projects funded by Natural Science Foundation of China (NSFC) and other foundations. He has authored or co-authored more than 100 peer-reviewed articles and textbook chapters. He also sits on the Editorial Board of Thoracic Cancer, Journal of Thoracic Disease, and several other academic journals. He has served as a chairman and member of the program committee for multiple international or national meetings, and he has delivered more than 30 live operation demonstrations at these meetings.

\section{Interview questions}

(I) In recent years, the technology of thoracic surgery has been persistently renewed. At the same time, some people think traditional surgery is on the skids. What do you think?

(II) What are the critical issues facing the field of minimally invasive thoracic surgery?

(III) With the increasing application of minimally invasive thoracic surgery, what trends can we observe in terms of perioperative complications?

(IV) Would you summarize the experience of West China Hospital in preventing perioperative complications, particularly in lung protection? 


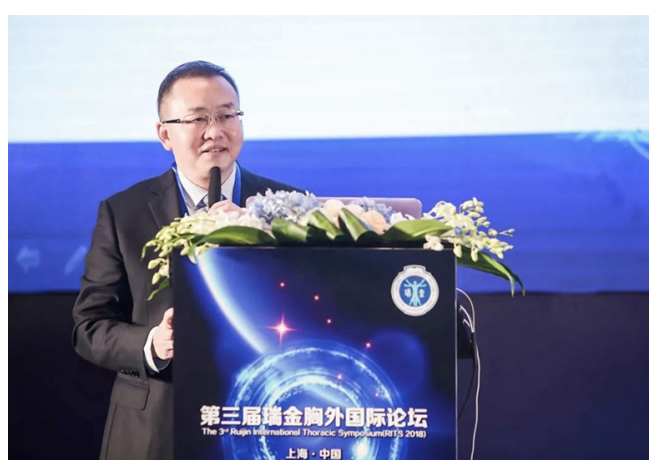

Figure 1 Prof. Lunxu Liu.

\section{Interview summary}

\section{New connotations and extensions of surgery}

Surgery has been an important means of treatment since ancient times. I believe it will not disappear in the short run, but given new connotations and extensions along with time.

Taking lung cancer surgery as an example, more than $70 \%$ of lung cancer patients in China are classified stage I. Surgery is still the only means to cure early lung cancer, and the effect is immediate. With the increasing screening rate of early lung cancer, the demand for surgery will only go up instead of down in the short run. This will come along with higher surgical standard, including more personalized treatment and more rapid rehabilitation.

This points the way for the future development of thoracic surgery. (I) Co-development of minimal invasion and fast recovery: Minimal invasion is the basis of fast recovery. While continuously renewing the minimally invasive techniques, we must continue to promote the concepts and practice of fast recovery; (II) further development of precision surgery: minimally invasive surgery reduces patient's trauma, but the specific implementation of the operation (e.g., which approach should be adopted under various circumstances) has to be further refined to strive for a more personalized and precise version of the surgery; (III) staying fully abreast of technological development: with the emergence of big data, artificial intelligence and other technologies, we are given more variability for the design and development of new surgical and therapeutic approaches; (IV) conducting more in-depth genomics research: this will allow more accurate analyses of tumor molecular typing, tumor staging and prognosis.

\section{Significant decline in the incidence of perioperative complications in thoracic surgery}

With the promotion of the concept of fast recovery and the widespread use of minimally invasive surgery in recent years, the incidence of perioperative complications in thoracic surgery has been greatly reduced. The incidence of complications such as pulmonary infection, deep vein thrombosis, pulmonary embolism, bronchopleural fistula, and esophageal anastomotic leakage has also been reduced significantly.

For the prevention of perioperative complications, West China Hospital has taken three effective measures in this regard. (I) To screen high-risk patients who are prone to complications, and formulate standard to identify if patients are suitable for surgery; (II) to establish a series of perioperative measures for high-risk or critically high-risk patients (especially preoperative sputum clearance, aerosol inhalation and other measures) to prevent complications; (III) to set up remedial measures for postoperative complications that has achieved two things-enabled patients to fulfil the required surgical conditions through preoperative pulmonary rehabilitation, and reduced the incidence of perioperative complications in high-risk patients.

\section{Acknowledgements}

The authors would like to thank Prof. Lunxu Liu for participating in the interview.

\section{Footnote}

Conflicts of Interest: The authors have no conflicts of interest to declare.

(Science Editors: Chen Gao, Brad Li, JTD, jtd@amepc.org)

Cite this article as: Gao C, $\mathrm{Li}$ B. Prof. Lunxu Liu: the demand for surgery will only go up instead of down. J Thorac Dis 2018;10(12):E855-E856. doi: 10.21037/jtd.2018.12.28 